\title{
Matrix metalloproteinases and their inhibitors as markers of inflammation and fibrosis in chronic liver disease (Review)
}

\author{
M. CONSOLO ${ }^{1}$, A. AMOROSO ${ }^{2}$, D.A. SPANDIDOS ${ }^{3}$ and M.C. MAZZARINO ${ }^{2}$ \\ Departments of ${ }^{1}$ Internal Medicine and Systemic Diseases, ${ }^{2}$ Biomedical Sciences, University of Catania, Catania, Italy; \\ ${ }^{3}$ Laboratory of Clinical Virology, Faculty of Medicine, University of Crete, Heraklion, Crete, Greece
}

Received May 7, 2009; Accepted May 27, 2009

DOI: 10.3892/ijmm_00000217

\begin{abstract}
Chronic liver disease (CLD) is a cause of morbidity and mortality worldwide, due to haemodynamic and metabolic complications of liver cirrhosis. During CLD the extracellular matrix undergoes a process of remodelling, leading to new collagen formation and deposition. Tissue remodelling is regulated by fine molecular mechanisms, involving proteases, inhibitors and growth factors. The major role in matrix degradation is played by matrix metalloproteinases (MMPs), a class of zinc and calcium-dependent enzymes, and their tissue inhibitors (TIMPs). Along with the progress in diagnostic techniques, leading to more precise and less invasive methods, the concept of monitoring has gained importance for the clinical management of CLD. At the present state of our knowledge, liver biopsy still represents an essential procedure for staging liver disease. However, despite its importance, liver biopsy presents some limitations: the risk of a disease underestimation is the most significant one, as hepatic lesions are often irregularly located within the liver. Parallel to the limitations of liver biopsy, clinical needs for an early identification of progressive fibrosis require additional non-invasive techniques to be developed. In this review we discuss the major problems concerning this important clinical necessity. Moreover, we focus on the role of MMPs and TIMPs in the pathogenesis of CLD, as well as their possible use as non-invasive serum markers for inflammation and fibrosis in this pathology.
\end{abstract}

\section{Contents}

1. Chronic inflammation and fibrosis in liver pathology

2. Matrix metalloproteinases in liver fibrosis

3. Current invasive and non-invasive techniques for liver disease staging and monitoring

4. Using MMPs and TIMPs as markers of liver fibrosis

Correspondence to: Professor M.C. Mazzarino, Department of Biomedical Sciences, University of Catania, Catania, Italy E-mail: clomazza@unict.it

Key words: matrix metalloproteinases, inflammation, fibrosis, chronic liver disease

\section{Chronic inflammation and fibrosis in liver pathology}

Chronic liver disease is a cause of morbidity and mortality worldwide (1). The major causes of mortality related to chronic liver disease are its haemodynamic and metabolic complications, such as hepatic failure, portal hypertension, encephalopathy, ascitis, esophageal haemorrhages and hepatorenal syndrome.

The major causes of chronic liver disease are viral B and $\mathrm{C}$ infections, which still remain widespread in many areas of the world. Other causes are alcohol abuse, primary or secondary haemochromatosis, Wilson's disease, and NASH $(2,3)$.

Liver cirrhosis can be defined as an alteration of hepatic parenchyma characterized by two major events: necrosis and regeneration. The initial cause of the injury determines the loss of hepatocytes due to both apoptotic and necrotic phenomena; the immune system, as well, can participate to hepatocyte loss either by inducing apoptotic signals or by directly mediating hepatocyte cell destruction (4). The loss of hepatic function activates an up to now undefined mechanism which leads viable hepatocytes to re-enter the cell cycle and divide by mitosis, to replace the lost cells. However, during hepatocyte regeneration, the extracellular matrix undergoes a process of remodelling, due to the persisting inflammatory stimulus, which leads to abnormal collagen deposition and consequently, to the fibrosis of the paren-chyma. Regenerating hepatocytes, therefore, are strangled within the fibrosis, resulting in an irregular regeneration and in the formation of nodules. Macronodules, micronodules and fibrosis are actually the macroscopic features of liver cirrhosis (5-7).

The microenvironment alterations responsible for hepatocyte regeneration, extracellular matrix remodelling and fibrosis are highly complex and not completely understood. All the cell types present in the liver seem to actively participate in the inflammation process, and consequently, in the fibrosis settlement. A high number of soluble factors are involved, and some of them could be used as markers to evaluate the clinical outcome. Many studies are still focusing on this aspect (8-10).

The extracellular matrix (ECM) during chronic liver disease (CLD) is different in quantity and quality from the physiological matrix. In healthy livers, collagen mainly consists of type I and type III, which are present in equal amounts, and 
is limited to the capsule, around the big vessels and in the portal areas. In perisinusoidal spaces, collagen is poor. When a fibrogenic injury occurs, both type I and type III collagen increase, though type I becomes more abundant. Moreover, fibrillar type IV collagen is deposited within perisinusoidal spaces, between endothelial sinusoidal cells and the vascular side of hepatocytes (Disse's spaces), resulting in the so-called sinusoid capillarization, where hepatic sinusoids lose their fenestrations, impairing the exchange of substances and the metabolic function of hepatocytes (11-13). Along with the sinusoidal deposition, fibrogenesis proceeds with the ECM expansion in the portal spaces and around the central lobular vein. Other ECM components such as glycosaminoglycans, fibronectin, elastin and laminin increase during fibrogenesis (14). A further phase is eventually characterized by the bridging fibrosis, connecting portal spaces to central vein. This process leads to two important phenomena: angiogenesis and the consequent shunt formation, in an attempt of the blood flow to overcome the increased resistance of liver parenchyma (portal hypertension). Abnormal vessel connections are therefore created between portal branches and hepatic veins. Liver fibrosis is a dynamic process, where progression and regression phases can be present alternatively during its evolution (15).

Such a bidirectional behaviour is however accompanied by a tissue remodelling process which leads finally to a switch of collagen types and, at further stages, to irreversible modifications of the liver parenchyma. Extracellular matrix is actually newly formed during this process, as well as reabsorbed. Fine molecular mechanisms regulate this balance, a broad range of molecules being involved such as proteases, inhibitors and growth factors (16). The major role in matrix degradation is, however, played by metalloproteinases, a class of zinc and calcium-dependent enzymes which are the focus of this review.

Among the cell types participating in the matrix remodelling, a leading position is held by hepatic stellate cells (HSC). These cells, situated in the perisinusoidal areas, are part of the hepatic stroma and make contact with other cells by their cytoplasmic arms. In healthy livers, HSC show a quiescent fat-storing phenotype and are rich in lipids and retinoids. Liver injury, however, leads to activation of HSC, which is associated to the loss of their storage function, consequent release of retinoids and their transformation into myofibro-blast-like cells, by the expression of $\alpha$-actin and consequent acquisition of contractile ability (17-19). Although a working knowledge of HSC is still incomplete, they are known to actively participate in matrix remodelling by producing different collagen types on one hand, and matrix metalloproteinases on the other, thus deeply influencing fibrosis progression and regression phenomena $(20,21)$. Other cells involved in collagen deposition are liver fibroblasts, and a newly characterized peripheral blood cell type called fibrocytes $(22,23)$.

\section{Matrix metalloproteinases in liver fibrosis}

Matrix metalloproteinases are a large family of calciumdependent, zinc-containing endopeptidases, which are responsible for the degradation of extracellular matrix proteins.

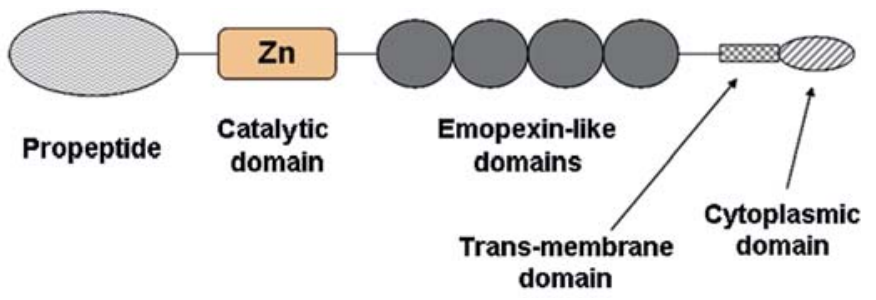

Figure 1. General structure of MMPs [modified from Blasi (27)].

As many other proteases, they are produced as inactive forms, zymogens, being eventually activated after they are released from cells (24-26). Presently, several different MMPs have been recognized. Most of them can act on a broad range of substrates including different collagen types, but also other ECM proteins such as fibronectin and laminin, elastin, proteoglycans, or even surface molecules (e.g., selectins) or growth factors.

The basic structure of a metalloproteinase consists of a zinc-containing catalytic domain (Fig. 1). In the zymogen forms the catalytic site contained in this domain is made inaccessible to the substrate by a pro-peptide which, by covering the catalytic site, prevents the substrate from interacting with it. During activation, the pro-peptide is cleaved, and the catalytic site becomes accessible to the substrate. Most MMPs possess different emopexin-like domains, next to the catalytic one. Such a modular structure allows MMPs to specifically interact with their inhibitors (TIMPs, tissue inhibitor of metalloproteinases). TIMPs bind to MMPs by recognizing two different sites; one site is located on to the emopexin-like domains, the other is the catalytic site. A special subgroup of metalloproteinases are membrane-bound (MT-MMPs). The members of this subgroup possess an additional trans-membrane sequence and an intracytoplasmic C-terminal tail (27-29) (Table I).

As in many other protease systems, the function of MMP inhibitors does not simply consist in blocking protease activity. The role of TIMPs is, actually, to modulate MMP function. According to a general behaviour in tissue biology, when an injury occurs, different protease systems are activated as a response to tissue damage; however, an increase of inhibitor molecules can be seen parallel to protease increase. In general, while damaged cells produce proteases, healthy cells produce inhibitors; alternatively, inhibitors are produced by surrounding cells different from the ones producing proteases (30-32). This is particularly evident in the coagulation cascade, and can also be seen in the liver, during chronic inflammation (33). However, this does not exclude the possibility that both proteases and inhibitors can be produced by the same cell type at the same moment. The nature of biological phenomena must not be forgotten, so that these assumptions should rather always be considered in terms of relative increases and alterations of physiological balances. Protease inhibition is, in conclusion, part of the proteolytic function, as it allows the regulation of the activity, as well as its space localization. The importance of the inhibitors is that they ensure the finalism of the protease activity.

The activation of MMPs requires a double proteolytic cleavage at the $\mathrm{N}$-terminal region where pro-peptide is located. 
Table I. Overview of MMPs and their alternative names.

\begin{tabular}{|c|c|c|}
\hline Class & MMP no. & Alternative name \\
\hline \multirow[t]{4}{*}{ Collagenases } & MMP-1 & Collagenase-1 \\
\hline & MMP-8 & Neutrophil collagenase \\
\hline & MMP-13 & Collagenase-3 \\
\hline & MMP-18 & Collagenase-4 \\
\hline \multirow[t]{2}{*}{ Gelatinases } & MMP-2 & Gelatinase-A \\
\hline & MMP-9 & Gelatinase-B \\
\hline \multirow[t]{5}{*}{ Stromelysins } & MMP-3 & Stromelysin-1 \\
\hline & MMP-10 & Stromelysin-2 \\
\hline & MMP-11 & Stromelysin-3 \\
\hline & MMP-27 & $51.6 \%$ homolog to \\
\hline & & Stromelysin-2 \\
\hline \multirow[t]{2}{*}{ Matrilysins } & MMP-7 & Matrilysin PU MP \\
\hline & MMP-26 & Matrilysin-2 \\
\hline \multirow{6}{*}{$\begin{array}{l}\text { Membrane type } \\
\text { (MT-MMPs) }\end{array}$} & MMP-14 & MT1-MMP \\
\hline & MMP-15 & MT2-MMP \\
\hline & MMP-16 & MT3-MMP \\
\hline & MMP-17 & MT4-MMP \\
\hline & MMP-24 & MT5-MMP \\
\hline & MMP-25 & MT6-MMP \\
\hline \multirow[t]{8}{*}{ Other enzymes } & MMP-12 & Macrophage metalloelastase \\
\hline & MMP-19 & RASI 1 \\
\hline & MMP-20 & Enamelysin \\
\hline & MMP-21 & Identified on chromosome 1 \\
\hline & MMP-22 & Identified on chromosome 1 \\
\hline & MMP-23 & From human ovary cDNA \\
\hline & MMP-28 & Epilysin \\
\hline & MMP-29 & Unnamed \\
\hline
\end{tabular}

The first cleavage can be operated by any activated protease such as plasmin, or other serin proteases. During this phase, a short peptide is released, while in the remaining part of the pro-petide a new amino acid sequence becomes accessible for the second cleavage. The second proteolytic attack must be operated by another MMP already activated: a second short peptide is released, and the MMP is finally activated, with its catalytic site free to interact with substrates. TIMPs also take part in the process of MMP activation. Their role is to bind to the emopexin-like domains of different MMPs, allowing them to get close enough to interact and activate each other (32). TIMPs are particularly important to facilitate the interactions between soluble MMPs to the membrane-bound ones, so that activation of soluble MMPs can occur at the cell-matrix interface, allowing cell migration through the matrix. This mechanism is particularly important for tumour cell metastases, but it can also be observed in the liver, during the ECM remodelling process in chronic hepatitis (34-36). The concentrations of TIMPs, and the MMPs/TIMPs ratio are critical for determining the actual proteatic activity. Low
TIMP concentrations, or a high MMPs/TIMPs ratio, allow activation of MMPs, while high TIMP concentrations lead to MMP inhibition of activation (37).

Although many studies have been performed on the MMPs/TIMPs imbalance during different pathological disorders, the great functional redundancy of different MMPinhibitor systems still represents an obstacle for completely understanding of the role of these proteins in different diseases. During chronic liver disease, the injury to liver parenchyma recognizes different mechanisms (38). Damaged and necrotic hepatocytes must therefore be removed by macrophages, which are called from the circulation into the liver parenchyma, while virus infected hepatocytes are recognized and destroyed by $\mathrm{T}$ cells. It is now well known that immune cells, especially during Th1-polarized responses, produce MMPs. Th1 immune responses are characterized by a strong cellular component (macrophages and $\mathrm{T}$ lymphocytes) and usually occur during acute inflammations or in the early phases of chronic inflammations (39-43). Once liver injury is triggered, resident liver cells are activated and change their phenotype. HSCs have been the object of great interest in recent years. As previously mentioned, once activated they change their fat-storing phenotype into a myofibroblast-like one. This change is evidenced by the expression of $\alpha$-smooth muscle actin, so that these cells acquire contractile ability. Activated HSC have been recognized to express a combination of various MMPs and TIMPs, in different phases of the disease. According to Benyon and Arthur (44), in the early phases of liver injury HSCs transiently express MMP-3, MMP-13 and uroplasminogen activator (uPA), and exhibit a matrix-degrading phenotype. In the later stages of liver injury, however, the pattern changes and the cells express a combination of MMPs that have the ability to degrade normal liver matrix, while inhibiting degradation of the fibrillar collagens that accumulate in liver fibrosis. This pattern is characterized by the combination of pro-MMP-2 and membrane type 1 (MT1)-MMP expression, which drive pericellular generation of active MMP-2 and local degradation of normal liver matrix. In addition there is a marked increase in expression of TIMP-1, leading to a more global inhibition of degradation of fibrillar liver collagens by interstitial collagenases (MMP-1/MMP-13). These pathways play a significant role in the progression of liver fibrosis. According to the same authors, however, regression of fibrosis is possible and, should the cause of liver injury be removed, the pattern reverses and TIMP-1 in particular is rapidly down-regulated. This phase is characterized by increasing activity of collagenases, degradation of liver matrix, and regression of liver fibrosis (45). In a study on rat liver parenchymal and non-parenchymal cells by Knittel et al (46), MMP and TIMP coding transcripts were detectable in all liver cell types, though the cellular expression levels were markedly different. In similar studies, performed by various authors, the conclusion drawn was that gelatinase-B (MMP-9) was predominantly expressed in Kupffer cells, gelatinase-A (MMP-2) in hepatic stellate cells and rat liver myofibroblasts, and stromelysin-1 (MMP-3), and -2 (MMP-10) in hepatic stellate cells, as well. Membrane type-1 MMP (MMP-14) was found in significant amounts in all liver cells, thus demonstrating the crucial importance of metallo- 
proteinase activation at the cell-matrix interface (47-49). TIMP-1 coding mRNAs were present mainly in hepatic stellate cells and rat liver myofibro-blasts, TIMP-2 additionally in Kupffer cells, while TIMP-3 expression was detectable only in hepatocytes. Interestingly, during in vitro activation of hepatic stellate cells, MMP expression was mostly down-regulated, while TIMP expression was enhanced, thereby providing an explanation for matrix accumulation during chronic liver disease. Moreover, this study provided a model for the effects of some cytokines of crucial importance during chronic hepatitis and fibrosis, such as TNF $\alpha$ and TGF- 1 1 (50-52). The results showed that TNF $\alpha$ stimulated both MMP and TIMP expression in hepatic stellate cells, while TGF- 11 only induced TIMP expression, thus providing confirming evidence for the profibrotic role played by TGF- $\beta 1$. Additional information can be obtained regarding the role of $\mathrm{TNF} \alpha$ in the initial matrix breakdown following liver injury.

From these data, two concepts began to be clarified: first, the inflammatory component of liver injury is crucial for matrix degradation; TNF $\alpha$ is a pro-inflammatory cytokine, and it supports ECM turnover, as well as immune reactions. The presence of membrane-bound MMPs on hepatocyte cell surface can be interpreted as an immune reaction, to facilitate the migration of immune cells. At the same time, however, it can be read as a response to a hepatocyte need. Activated hepatocytes re-enter the cell cycle during chronic liver disease. So, membrane-bound MMPs can also be seen as an attempt to create space for regeneration. However, any reparative response needs to stop inflammation. This is what happens in further stages of chronic liver disease, where antiinflammatory and profibrotic cytokines like TGF- $\beta 1$ are produced, and fibroblasts are recruited. In these stages, TIMP production overcomes that of MMPs, therefore, new extracellular matrix is synthesized (53-57). Activated HSCs have also been shown to be an important source of interstitial collagens, including fibrillar collagens type I and type III which determine fibrosis. Previous studies have shown a TIMP increase in alcoholic liver disease $(33,58-60)$, and that TIMP-1 expression is five times upregulated in cirrhotic compared to normal liver. Studies conducted on billiary atresia showed that also bile ductular epithelial cells, as well as Kupffer cells and hepatocytes produce MMP-7. These studies revealed also a significant positive correlation between MMP-7 immunostaining positivity with the stages of liver fibrosis (61). In another animal alcohol induced liver fibrosis model (62), TIMP-1 was found to be the most powerful factor determining sinusoid capillarization and perisinusoidal fibrosis; at the same time, TIMP-2 was the most effective regulator on the metabolism of type IV collagen located in the basement of sinus.

Although many aspects are still to be clarified on the mechanisms of fibrosis resolution, it is clear that fibrosis deposition during CLD proceeds parallel to a general reorganization of the ECM in the liver parenchyma; this ECM reorganization is finely regulated by complex proteatic systems such as those of MMPs and their inhibitors. Because of their recognized important involvement in the liver fibrosis pathogenesis, many researchers have started investigating the possible use of MMPs and TIMPs as prognostic markers, in the attempt to find a valid alternative to the use of liver biopsy to detect fibrosis. Although definite conclusions have not been made, many studies have been developed by correlating serum levels of MMPs and TIMPs to their hepatic levels, and also to fibrosis settlement. Before examining this part of literature, we reported on present methods, needs and problems of liver disease staging.

\section{Current invasive and non-invasive techniques for liver disease staging and monitoring}

Chronic liver diseases embrace a variety of hepatic pathologies with different aetiology and severity, but where the necroinflammatory process lasts at least 6 months. Regardless of their heterogeneity, CLD share many of their clinical, serological and histopathological features. The histopathological evaluation of localization, extension and severity of hepatic injury, in its inflammatory and fibrotic components, holds great prognostic value. However, as interindividual differences are present, histopathological features are insufficient to fully characterize a CLD. Together with improvement in the diagnostic techniques, leading to more precise and less invasive methods, the concept of monitoring has gained importance, as well as the possibility to detect early indices, predictive of a negative prognosis. The major life-threatening complications in CLD are likely to be related to severity and extension of liver injury, while being relatively independent from the duration of the disease (63). A deeper understanding of the pathogenetic mechanisms occurring in CLD, and the consequent early detection of the steps leading to fibrosis and cirrhosis, represents a crucial goal for diagnostics in hepatology, as it would greatly improve the monitoring possibilities, and the quality of life of the patients.

At the present state of our knowledge, liver biopsy still represents an essential procedure for staging liver disease. In order to give an objective evaluation of the histopathological patterns, and satisfy such a clinical necessity, different scoring systems have been developed. The simplest scoring system, the Metavir score, was specifically created for staging liver injury occurring in chronic viral $\mathrm{C}$ hepatitis. Two parameters are considered: extension of inflammatory cell infiltration, as a measure for the activity of hepatitis (grading), and extension of fibrotic bridles (staging). The histological activity index (HAI), developed by Knodell, first, and modified by Ishak, despite its complexity, aims to achieve a greater prognostic value (64).

However, despite its importance, liver biopsy presents some limitations. The risk of a disease underestimation is the most significant one, as hepatic lesions are often randomly located within the liver. Some studies have reported this risk to be $20-50 \%$ of all cases (65). Moreover, the scoring systems based on liver biopsy assume a linear increase in the severity of fibrosis between stages, while it has been clearly shown that a greater increase of severity occurs in he highest stages (66). Other limitations are related to its invasive nature, such as pain and the risk of peritonitis and hypotension.

Parallel to the limitations of liver biopsy, clinical needs for identification of the risk factors for progressive fibrosis require additional non-invasive techniques to be developed. There is evidence showing that even advanced fibrosis might 
be reversible, so that the research for antifibrotic therapies is gaining interest (67). From this perspective, the need for an early and regular monitoring of response will greatly exceed the possibilities given by liver biopsy. It is also reasonable to think that a continuous variable such as fibrosis could be better described by a continuous spectrum of marker values, instead of being enclosed in stages.

Several predictive serum-based tests have been evaluated for fibrosis and cirrhosis (68-72). The predictive value of single markers has been studied, as well as the one given by combinations of different markers calculated by algorithms. Although no ideal marker exists, as most are not liver specific or are affected by inflammation or other pathologies, from the great number of studies already carried out, it is possible to conclude that single markers often correlate well with cirrhosis; however, diagnostic accuracy for fibrosis is greater in studies using multiple markers. The most significant serum markers and models for fibrosis prediction are briefly discussed below. Nevertheless, it is worth remembering that conventional tests of liver function, although they do not directly assess liver fibrosis or cirrhosis, still provide important information to the clinician about occurring liver damage (AST, ALT) as well as liver biosynthetic capacity (albumin, PT). The development of new markers and indices should not exclude the possibility of a re-evaluation of such conventional markers (73-79).

Among the collagen markers, the $\mathrm{N}$-terminal propeptide of type III collagen (PIIINP) has been validated in alcoholic liver disease, hepatitis $\mathrm{C}$, and non-alcoholic fatty liver disease. Serum levels increase with the degree of liver fibrosis (80).

Serum levels of hyaluronic acid (HA) are elevated in various chronic liver diseases, due to production by hepatic stellate cells and decreased clearance by sinusoidal endothelial cells. Serum levels correlate with liver fibrosis in alcoholic liver disease and chronic hepatitis C (81-83).

Serum concentrations of $\alpha 2-$ Macroglobulin, produced by hepatocytes and stellate cells, also positively correlate with liver fibrosis. A negative correlation has been seen for serum levels of A1 apolipoprotein and haptoglobin (84-86).

Matrix metalloproteinases and TIMPs have also been correlated to liver fibrosis. The literature concerning this topic is reviewed in the next section.

Among the serum models using multiple markers, FibroTest was published in 2001, initially applied to HCVrelated chronic hepatitis. Further, it has also been applied to chronic hepatitis B infection and to non-alcoholic fatty liver disease (NashTest). A combination of five markers is used to generate a score: Apo A1, haptoglobin, $\alpha 2$-Macroglobulin $(\alpha 2-\mathrm{M}), \gamma$-glutamyl transpeptidase $(\gamma-\mathrm{GT})$ activity and bilirubin, together with age and gender of the patients. Height, weight, serum triglycerides, cholesterol, AST and ALT are added in the NashTest. Scores from 0 to 0.10 provide a negative predictive value for the presence of significant fibrosis ranging from $100 \%$ to $85 \%$, according to different validations. Scores from 0.60 to 1.00 have $90-78 \%$ positive predictive value for significant fibrosis. Scores from 0.11 to 0.59 are considered indeterminate and liver biopsy is recommended in these cases (87-89).

FIBROspect was first developed in 2004 for hepatitis C patients. Three serum markers are used: $\alpha 2-\mathrm{M}$, hyaluronic acid and TIMP-1. Both positive and negative predictive values for presence or absence of fibrosis are around $75 \%$. The cutoff score is $0.36(90,91)$.

Hepascore is a score from 0.00 to 1.00 calculated from the measurement of serum bilirubin, $\gamma$-GT activity, $\alpha 2-\mathrm{M}$ and hyaluronic acid levels, plus age and sex of the patient. It has been validated in hepatitis $C$ patients, where a score $\geq 0.50$ provided a positive predictive value of $88 \%$ for significant fibrosis, and a score $<0.50$ had a negative predictive value of 95\% for the absence of advanced fibrosis (92).

Other scores have been developed such as Fibrometer, and the algorithm created by the European Liver Fibrosis Group (ELFG). Fibrometer uses six markers: platelets, PT index, AST, $\alpha 2-\mathrm{M}$, hyaluronic acid and urea. The ELFG score combines age of the patient with serum concentrations of hyaluronic acid, PIIINP and TIMP-1. This algorithm has been applied to hepatitis $\mathrm{C}$, alcoholic liver disease and nonalcoholic fatty liver disease. The predictive values of these models were similar to the other models $(93,94)$.

Several non-invasive diagnostic imaging tests for fibrosis and cirrhosis, which do not involve testing serum, have been evaluated, among which noteworthy is the transient elastography (Fibroscan). Transient elastography is based on ultrasounds, and it aims to assess liver fibrosis by measuring elastic properties of liver parenchyma and liver stiffness. Liver stiffness measurement can accurately diagnose advanced liver fibrosis, but its performance in early liver fibrosis is less satisfactory. Some authors have stated that transient elastography gives a performance in assessing liver fibrosis similar to FibroTest; however, it is interesting to note that a better performance can be given by combining transient elastography and FibroTest. It has been suggested that using this combination, $84 \%$ of hepatitis $\mathrm{C}$ patients could have avoided biopsy $(95,96)$.

\section{Using MMPs and TIMPs as markers of liver fibrosis}

What can be summarized from a re-examination of literature concerning the use of MMPs and TIMPs as biomarkers for fibrosis is, that they basically have a positive predictive value lower than liver biopsy when used as single markers. Using them in combination with other markers, however, is reasonable proving a promising approach. Several studies have been developed, trying to assess the correlation with serum or plasma concentrations of different MMPs and TIMPs and liver fibrosis or cirrhosis. Before analyzing some of the most recent and significant works, it is important to stress some aspects which must be taken into consideration when assessing the validity of a serum marker for fibrosis. First, a homogeneous set of patients in terms of liver disease type and treatment is required. An accurate selection must be applied, to avoid interference with other inflammatory conditions; though MMPs and TIMPs reflect hepatocyte injury or necro-inflammatory activity, they are not liver fibrosis-specific. A further problem is that differences in assays and/or lack of agreement about those that can be considered as the normal values of these markers negatively influence published cut-off values of serum model scores.

Despite these difficulties, however, a first goal has been reached by non-invasive fibrosis markers, as very low levels of 
the serum markers usually have very high negative predictive values; therefore, it has been suggested that liver biopsy could be spared in these patients, as they have a very low probability of significant fibrosis (97-99).

Among the most recent studies regarding serum models (100), the use of a panel of circulating markers was evaluated in order to determine liver fibrosis staging. In this study 194 $\mathrm{HCV}+$ patients underwent liver biopsy before receiving antiviral treatment. They were eventually compared with 194 healthy controls. Serum levels of hyaluronate, PIIINP, MMP-1, MMP-2, MMP-9, TIMP-1 and TIMP-2 were determined by RIA and ELISA. Histological lesions were staged according to METAVIR score. Hyaluronate, PIIINP, TIMP-1, and TIMP-2 were found increased compared to the controls, and a correlation with fibrosis was observed.

A second study was carried out to validate an index combining serum concentrations of PIIINP, HA, MMP-1, MMP-9 and TIMP-1 in $79 \mathrm{HCV}+$ patients treated with INF- $\alpha$ and ribavirin for 24-48 weeks, to assess their variations during antiviral treatment (101). HA and TIMP-1 serum concentrations were also found significantly lower at the end of follow-up in responder patients, but early changes were minimal and not influenced by the response to treatment.

In another study (102), serum levels of MMP-2 and TIMP-1 were used as non-invasive parameters for liver fibrosis diagnosis by comparing them with histological diagnosis and with conventional liver function tests in 41 patients with HCV-related chronic liver disease and 10 healthy controls. Among the 41 patients, 14 had histologically proven liver cirrhosis. Hepatic histology was evaluated using the histological activity index according to Ishak. The results were that MMP-2 serum levels were similar in controls and in chronic hepatitis $C$ patients with $(n=15)$ and without $(n=12)$ fibrosis, but increased significantly in cirrhosis. TIMP-1 serum values showed a steady increase from normal controls to chronic hepatitis $\mathrm{C}$ without fibrosis, hepatitis $\mathrm{C}$ with fibrosis, and cirrhosis. The diagnostic potential of MMP-2 to detect fibrosis was low with a sensitivity of $7 \%$ and a diagnostic efficiency of $56 \%$. The diagnostic potential of circulating MMP-2 to detect cirrhosis was higher with a sensitivity of $83 \%$ and a specificity of $96 \%$, resulting in a diagnostic efficiency of $92 \%$. Serum TIMP-1 values detected fibrosis with a sensitivity of $67 \%$ and a specificity of $69 \%$ resulting in an efficiency rate of $70 \%$. TIMP-1 values detected cirrhosis with $100 \%$ sensitivity but only $75 \%$ specificity. The diagnostic potential of circulating TIMP-1 was higher than the one of serum ALT, AST or albumin values. The conclusions were that serum values of MMP-2 and TIMP-1 are able to detect cirrhosis with a high sensitivity; moreover, regular determinations of both TIMP-1 and MMP-2 in patients with chronic hepatitis C may be used as indicators of increasing fibrosis and the development of cirrhosis.

A study on HCV infected Egyptian patients evaluated 109 patients with detectable HCV by RT-PCR (103). The patients were classified into three different pathological stages and grades. The different clinical, biochemical, virological and ultra-sonographic parameters were assessed and analyzed, and the variables that showed significant association with histopathological staging or grading were included in multivariate logistic regression analysis. The regression model revealed that, platelet count, matrix MMP-9, portal vein diameter, splenic longitudinal axis, ALT, AST and viral load were the factors that provided significance to the model. From these findings a new score was generated ranging from 0 to 9 . The score model was applied to the patients to assess its validity where it proved to be accurate in discriminating patients with mild inflammation and fibrosis (sensitivity $81.8 \%$, specificity $80.5 \%$ and accuracy $80.7 \%$ ) and more accurate in detecting patients with cirrhosis (sensitivity $80 \%$, specificity $96.6 \%$ and accuracy $93.6 \%$ ), but less accurate in detecting patients with moderate to severe fibrosis (sensitivity $68.7 \%$, specificity $66.7 \%$, accuracy $67.9 \%$ ). The study concluded that, the score model could not completely replace liver biopsy but at least it could be used to substantially reduce the number of liver biopsies to assess disease progression during follow-up in patients with chronic HCV infection. Moreover, the authors underlined how the score could be used to make decisions on treatment in patients who have contraindications to or who refuse liver biopsy.

In other studies, in order to clarify whether circulating MMPs and their tissue inhibitors TIMPs could be used as serum markers of fibroproliferation in chronic liver diseases the expression of MMP-2, MMP-9, TIMP-1 and TIMP-2 in peripheral blood mononuclear leukocytes and polymorphonuclear leukocytes were studied by RealTime-PCR. The authors later compared the intracellular expression to the circulating concentrations of the same markers, and correlated them to hepatic histology, in patients with chronic active $\mathrm{C}$ hepatitis (CAH) (104). Twenty healthy controls were recruited, as well as 40 patients with $\mathrm{CAH}$ and 20 patients with hepatitis C-induced cirrhosis. MMP-2 mRNA was found almost exclusively in the liver, while MMP-9 mRNA was found in leukocytes. TIMP RNA-equivalents were decreased in mononuclear cells of $\mathrm{CAH}$ patients, but neither MMP-9 nor TIMP RNA expression showed any correlation to the extent of inflammation or fibrosis. MMP-2 and TIMP-1 protein concentrations were increased in cirrhotic patients though they showed a wide overlap in $\mathrm{CAH}$ patients and healthy controls. MMP-9 values were lower in $\mathrm{CAH}$ and cirrhotic patients than in healthy controls. TIMP-2 values showed a wide overlap in all three groups. The MMP-2/ TIMP-1 and MMP-9/TIMP-1 ratios were lower in cirrhotic patients than in healthy controls; the MMP-2/TIMP-2 and MMP-9/TIMP-2 ratios were not different. Peripheral blood cell expression of MMP-2, MMP-9, and TIMPs revealed no correlation with the circulating concentrations of these proteins. Circulating TIMP-1 and the MMP-2/TIMP-1 ratio correlated to the inflammatory activity in liver biopsies, but only the circulating MMP-2/TIMP-1 ratio also correlated with the histological degree of fibrosis. Thus, circulating MMP-2/ TIMP-1 ratio could be further evaluated as a progression marker in patients with chronic liver disease.

As an attempt to investigate the liver specific MMP and TIMP expression, liver mRNA levels of MMP-2, MMP-7 and MMP-9, TIMP-1, TIMP-2 and TIMP-3 have been analyzed and correlated to the histological stage of the disease and to the procollagen IV liver mRNA levels in 29 patients with chronic active $\mathrm{C}$ hepatitis and 7 patients with HCV-related endstage liver cirrhosis (105). The results showed that from normal livers to cirrhosis both TIMP and MMP RNA levels increased. 
However, none of the RNA levels differed significantly between chronic active hepatitis patients with and without fibrosis. These results also provided further confirmation of the trend of MMP-2 and TIMP-1 as the best discriminators between cirrhosis and pre-cirrhotic stages. MMP-7 mRNA levels were also found to follow the tendency of MMP-2 and TIMP-1. The three markers correlated with histologic and biochemical inflammatory activity and with procollagen IV intrahepatic mRNA levels.

Many studies have highlighted the role of the MMPs and TIMPs in the fibrogenesis in response to treatment based on INF $\alpha$ and ribavirin. A study was performed on the effects of INF $\alpha$ on hepatic metabolism during fibrotic stages of CLD, as well as to monitor serum concentrations of TIMP-1 and PIIINP, reflecting fibrolysis and fibrogenesis, respectively (106). Serum levels of TIMP-1 and PIIINP were serially measured in 112 treated and 31 untreated patients with chronic hepatitis $\mathrm{C}$ during and after interferon- $\alpha$ treatment. Serum pre-treatment levels of both markers were significantly higher in non-responders than in sustained and transient responders. Moreover, serum TIMP-1 levels decreased significantly during and after treatment in sustained responders, and decreased temporarily at the end of treatment in transient responders, while they remained unchanged during and after treatment in non-responders and untreated patients. Serum PIIINP levels decreased significantly during and after treatment in all treated groups. Histological examination 12 months after interferon was completed demonstrated, intriguingly, that hepatic fibrosis improved in sustained responders while was unchanged in transient and non-responders; it also progressed in untreated patients. According to the authors, the results suggested that INF $\alpha$ treatment of chronic $\mathrm{C}$ hepatitis may improve hepatic fibrosis in sustained responders by the acceleration of fibrolysis as well as the inhibition of fibrogenesis, and that it may suppress the progression of hepatic fibrosis in non-sustained responders by the inhibition of fibrogenesis.

Regulatory elements involved in liver fibrosis, such as platelet derived growth factor-BB (PDGF-BB) and transforming growth factor- $\beta 1$ (TGF- $\beta 1$ ), have been studied along with MMP-1 and TIMP-1, to determine whether these molecules could be used as indices for the diagnosis of hepatic fibrosis (107). Serum samples from 60 patients with chronic viral hepatitis $\mathrm{B}$ and 20 healthy blood donors were assayed to determine the level of PDGF-BB, TGF-B1, MMP-1, and TIMP-1 by ELISA technique. The expression of TIMP-1 mRNA and MMP-1 mRNA in peripheral blood mononuclear cells (PBMCs) was detected by RT-PCR. Liver biopsy was performed in all patients, and the biopsy samples were histopathologically examined. Serum levels of PDGFBB, TIMP-1 and MMP-1, as well as TIMP-1 mRNA and MMP-1 mRNA levels in PBMCs were significantly higher in the patients than in healthy controls. Moreover, serum levels of PDGF-BB, TIMP-1, TIMP-1/MMP-1 ratio, and TIMP-1 mRNA were positively correlated with fibrosis stage and inflammation grade, while serum levels of MMP-1 were negatively correlated. TIMP-1 mRNA/MMP-1 mRNA ratio was also positively correlated with inflammation grade. In conclusion, serum PDGF-BB proved the most valuable marker, and its sensitivity was the highest among the indices.
The markers with the highest specificity were TIMP-1 mRNA, and TIMP-1 mRNA/MMP-1 mRNA ratio.

From the data present in literature and herein reviewed, it is possible to conclude that the use of MMPs and/or TIMPs as non-invasive markers of inflammation and fibrosis in CLD is possible and offers promising perspectives. From a long experience in the use of liver biopsy it is now clear that biopsy cannot be considered as the ideal solution for every circumstance; liver biopsy can fail an exact estimation of the disease as every other test and, most importantly, it cannot be repeated unlimitedly. From this point of view the research for auxiliary methods of liver disease staging appears reasonable. The present data on MMPs and TIMPs show interesting possibilities for the use of these molecules, as they could provide a good contribution in terms of sensitivity and specificity, if used in combination with other parameters within algorithms. What can be suggested from the data reviewed here is that more studies with lager number of patients and healthy controls are needed, to acquire the necessary experience. Importantly, homogeneous methods and techniques should be used for measuring the serum levels. A reasonably integrated approach should be found comprising serum markers, liver biopsy, as well as diagnostic imaging techniques such as ultrasonography and transient elastography.

\section{Acknowledgements}

The present study was supported by the funds of Dottorato di Ricerca in 'Nuovi Sistemi di Valutazione e Studio delle Complicanze Emodinamiche e Metaboliche delle Epatopatie Croniche', University of Catania, Italy.

\section{References}

1. Alter MJ: Hepatitis C virus infection in the United States. J Hepatol 31 (Suppl 1): 88-91, 1999.

2. Honeycutt AA, Harris JL, Khavjou O, Buffington J, Jones TS and Rein DB: The costs and impacts of testing for hepatitis C virus antibody in public STD clinics. Public Health Rep 122 (Suppl 2): 55-62, 2007.

3. Missiha SB, Ostrowski M and Heathcote EJ: Disease progression in chronic hepatitis $\mathrm{C}$ : modifiable and nonmodifiable factors. Gastroenterology 134: 1699-1714, 2008.

4. Malhi $\mathrm{H}$ and Gores GJ: Cellular and molecular mechanisms of liver injury. Gastroenterology 134: 1641-1654, 2008.

5. Malato Y, Sander LE, Liedtke C, Al-Masaoudi M, Tacke F, Trautwein $\mathrm{C}$ and Beraza N: Hepatocyte-specific inhibitor-ofkappaB-kinase deletion triggers the innate immune response and promotes earlier cell proliferation during liver regeneration. Hepatology 47: 2036-2050, 2008.

6. Saile B and Ramadori G: Inflammation, damage repair and liver fibrosis-role of cytokines and different cell types. Z Gastroenterol 45: 77-86, 2007.

7. Rappaport AM, MacPhee PJ, Fisher MM and Phillips MJ: The scarring of the liver acini (Cirrhosis). Tridimensional and microcirculatory considerations. Virchows Arch A Pathol Anat Histopathol 402: 107-137, 1983.

8. Ebrahimkhani MR, Elsharkawy AM and Mann DA: Wound healing and local neuroendocrine regulation in the injured liver. Expert Rev Mol Med 10: e11, 2008.

9. Iredale J: Defining therapeutic targets for liver fibrosis: exploiting the biology of inflammation and repair. Pharmacol Res 58: 129-136, 2008.

10. Tangkijvanich $P$ and Yee HF Jr: Cirrhosis - can we reverse hepatic fibrosis? Eur J Surg 587 (Suppl): 100-112, 2002.

11. Guo J and Friedman SL: Hepatic fibrogenesis. Semin Liver Dis 27: 413-426, 2007.

12. Limmer A and Knolle PA: Liver sinusoidal endothelial cells: a new type of organ-resident antigen-presenting cell. Arch Immunol Ther Exp (Warsz) 49 (Suppl): S7-S11, 2001. 
13. Wisse E, Braet F, Luo D, De Zanger R, Jans D, Crabbé E and Vermoesen A: Structure and function of sinusoidal lining cells in the liver. Toxicol Pathol 24: 100-111, 1996.

14. Arii S and Imamura M: Physiological role of sinusoidal endothelial cells and Kupffer cells and their implication in the pathogenesis of liver injury. J Hepatobiliary Pancreat Surg 7: 40-48, 2000.

15. Bolarin DM and Azinge EC: Biochemical markers, extracellular components in liver fibrosis and cirrhosis. Nig Q J Hosp Med 17: 42-52, 2007

16. Gieling RG, Burt AD and Mann DA: Fibrosis and cirrhosis reversibility - molecular mechanisms. Clin Liver Dis 12: 915-937, 2008.

17. Mutsaers SE, Bishop JE, McGrouther G and Laurent GJ: Mechanisms of tissue repair: from wound healing to fibrosis. Int J Biochem Cell Biol 29: 5-17, 1997.

18. Vu TH and Werb Z: Matrix metalloproteinases: effectors of development and normal physiology. Genes Dev 14: 2123-2133, 2000.

19. Friedman SL: Hepatic stellate cells: protean, multifunctional, and enigmatic cells of the liver. Physiol Rev 88: 125-172, 2008.

20. Cisneros L, Londoño MC, Blasco C, Bataller R, Miquel R, Bruguera M, Ginès $P$ and Rimola A: Hepatic stellate cell activation in liver transplant patients with hepatitis $\mathrm{C}$ recurrence and in non-transplanted patients with chronic hepatitis C. Liver Transpl 13: 1017-1027, 2007.

21. Enami Y, Bandi S, Kapoor S, Krohn N, Joseph B and Gupta S: Hepatic stellate cells promote hepatocyte engraftment in rat liver after prostaglandin-endoperoxide synthase inhibition. Gastroenterology (In press).

22. Russo FP, Alison MR, Bigger BW, Anofah E, Florou A, Amin F, Bou-Gharios G, Jeffery R, Iredale JP and Forbes SJ: The bone marrow functionally contributes to liver fibrosis. Gastroenterology 130: 1807-1821, 2006.

23. Forbes SJ, Russo FP, Rey V, Burra P, Rugge M, Wright NA and Alison MR: A significant proportion of myofibroblasts are of bone marrow origin in human liver fibrosis. Gastroenterology 126: 955-963, 2004

24. Muroski ME, Roycik MD, Newcomer RG, van den Steen PE, Opdenakker G, Monroe HR, Sahab ZJ and Sang QX: Matrix metalloproteinase-9/gelatinase B is a putative therapeutic target of chronic obstructive pulmonary disease and multiple sclerosis. Curr Pharm Biotechnol 9: 34-46, 2008.

25. Sasaki M, Kashima M, Ito T, Watanabe A, Izumiyama $N$, Sano M, Kagaya M, Shioya T and Miura M: Differential regulation of metalloproteinase production, proliferation and chemotaxis of human lung fibroblasts by PDGF, interleukin-1beta and TNF-alpha. Mediators Inflamm 9: 155-160, 2000.

26. Morgia G, Falsaperla M, Malaponte G, Madonia M, Indelicato M, Travali S and Mazzarino M: Matrix metalloproteinases as diagnostic (MMP-13) and prognostic (MMP-2, MMP-9) markers of prostate cancer. Urol Res 33: 44-50, 2005.

27. Blasi F: Proteolisi extracellulare. Farmacologia generale e molecolare. UTET 14: 178-189, 2003.

28. Pardo A and Selman M: MMP-1: the elder of the family. Int J Biochem Cell Biol 37: 283-288, 2005.

29. Iyer S, Visse R, Nagase H and Acharya KR: Crystal structure of an active form of human MMP-1. J Mol Biol 362: 78-88, 2006.

30. Iyer S, Wei S, Brew K and Acharya KR: Crystal structure of the catalytic domain of matrix metalloproteinase-1 in complex with the inhibitory domain of tissue inhibitor of metalloproteinase-1. J Biol Chem 282: 364-371, 2007.

31. Hamze AB, Wei S, Bahudhanapati H, Kota S, Acharya KR and Brew K: Constraining specificity in the $\mathrm{N}$-domain of tissue inhibitor of metalloproteinases-1; gelatinase-selective inhibitors. Protein Sci 16: 1905-1913, 2007.

32. Will H, Atkinson SJ, Butler GS, Smith B and Murphy G: The soluble catalytic domain of membrane type 1 matrix metalloproteinase cleaves the propeptide of progelatinase A and initiates autoproteolytic activation. Regulation by TIMP-2 and TIMP-3. J Biol Chem 271: 17119-17123, 1996

33. Arthur MJ, Iredale JP and Mann DA: Tissue inhibitors of metalloproteinases: role in liver fibrosis and alcoholic liver disease. Alcohol Clin Exp Res 23: 940-943, 1999.

34. Salguero Palacios R, Roderfeld M, Hemmann S, Rath T, Atanasova S, Tschuschner A, Gressner OA, Weiskirchen R, Graf J and Roeb E: Activation of hepatic stellate cells is associated with cytokine expression in thioacetamide-induced hepatic fibrosis in mice. Lab Invest 88: 1192-1203, 2008

35. McCrudden R and Iredale JP: Liver fibrosis, the hepatic stellate cell and tissue inhibitors of metalloproteinases. Histol Histopathol 15: $1159-1168,2000$
36. Knittel T, Mehde M, Kobold D, Saile B, Dinter C and Ramadori G: Expression patterns of matrix metalloproteinases and their inhibitors in parenchymal and non-parenchymal cells of rat liver: regulation by TNF-alpha and TGF-beta1. J Hepatol 30: 48-60, 1999.

37. Nagase H, Visse R and Murphy G: Structure and function of matrix metalloproteinases and TIMPs. Cardiovasc Res 69: 562-573, 2006

38. Knolle PA and Gerken G: Local control of the immune response in the liver. Immunol Rev 174: 21-34, 2000.

39. Baroni GS, Pastorelli A, Manzin A, Benedetti A, Marucci L, Solforosi L, Di Sario A, Brunelli E, Orlandi F, Clementi M and Macarri G: Hepatic stellate cell activation and liver fibrosis are associated with necroinflammatory injury and Th1-like response in chronic hepatitis C. Liver 19: 212-219, 1999.

40. Carpino G, Morini S, Ginanni Corradini S, Franchitto A, Merli M, Siciliano M, Gentili F, Onetti Muda A, Berloco P, Rossi M, Attili AF and Gaudio E: Alpha-SMA expression in hepatic stellate cells and quantitative analysis of hepatic fibrosis in cirrhosis and in recurrent chronic hepatitis after liver transplantation. Dig Liver Dis 37: 349-356, 2005.

41. Friedman SL: Mechanisms of hepatic fibrogenesis. Gastroenterology 134: 1655-1669, 2008.

42. Goetzl EJ, Banda MJ and Leppert D: Matrix metalloproteinases in immunity. J Immunol 156: 1-4, 1996.

43. Oviedo-Orta E, Bermudez-Fajardo A, Karanam S, Benbow U and Newby AC: Comparison of MMP-2 and MMP-9 secretion from $\mathrm{T}$ helper 0,1 and 2 lymphocytes alone and in coculture with macrophages. Immunology 124: 42-50, 2008.

44. Benyon RC and Arthur MJ: Extracellular matrix degradation and the role of hepatic stellate cells. Semin Liver Dis 21: 373-384, 2001

45. Kisseleva T and Brenner DA: Hepatic stellate cells and the reversal of fibrosis. J Gastroenterol Hepatol 21 (Suppl 3): S84-S87, 2006.

46. Knittel T, Mehde M, Grundmann A, Saile B, Scharf JG and Ramadori G: Expression of matrix metalloproteinases and their inhibitors during hepatic tissue repair in the rat. Histochem Cell Biol 113: 443-453, 2000.

47. Li XY, Ota I, Yana I, Sabeh F and Weiss SJ: Molecular dissection of the structural machinery underlying the tissue-invasive activity of MT1-MMP. Mol Biol Cell 19: 3221-3233, 2008.

48. Evans RD and Itoh Y: Analyses of MT1-MMP activity in cells. Methods Mol Med 135: 239-249, 2007.

49. Sohail A, Sun Q, Zhao H, Bernardo MM, Cho JA and Fridman R: MT4-(MMP17) and MT6-MMP (MMP25), a unique set of membrane-anchored matrix metalloproteinases: properties and expression in cancer. Cancer Metastasis Rev 27: 289-302, 2008.

50. Urtasun R, Cubero FJ, Vera M and Nieto N: Reactive nitrogen species switch on early extracellular matrix remodeling via induction of MMP1 and TNFalpha. Gastroenterology 136: 1410-1422, 2009.

51. Préaux AM, Mallat A, Nhieu JT, D'Ortho MP, Hembry RM and Mavier P: Matrix metalloproteinase-2 activation in human hepatic fibrosis regulation by cell-matrix interactions. Hepatology 30: 944-950, 1999 .

52. Bissell DM: Chronic liver injury, TGF-beta, and cancer. Exp Mol Med 33: 179-190, 2001.

53. Wullaert A, van Loo G, Heyninck K and Beyaert R: Hepatic tumor necrosis factor signaling and nuclear factor-kappaB: effects on liver homeostasis and beyond. Endocr Rev 28: 365-386, 2007.

54. Gressner OA, Rizk MS, Kovalenko E, Weiskirchen R and Gressner AM: Changing the pathogenetic roadmap of liver fibrosis? Where did it start; where will it go? J Gastroenterol Hepatol 23: 1024-1035, 2008.

55. Matsuzaki K, Murata M, Yoshida K, Sekimoto G, Uemura Y, Sakaida N, Kaibori M, Kamiyama Y, Nishizawa M, Fujisawa J, Okazaki $\mathrm{K}$ and Seki T: Chronic inflammation associated with hepatitis $\mathrm{C}$ virus infection perturbs hepatic transforming growth factor beta signaling, promoting cirrhosis and hepatocellular carcinoma. Hepatology 46: 48-57, 2007.

56. Liu X, Hu H and Yin JQ: Therapeutic strategies against TGF-beta signaling pathway in hepatic fibrosis. Liver Int 26: 8-22, 2006.

57. Liu X, Wang W, Hu H, Tang N, Zhang C, Liang W and Wang M: Smad3 specific inhibitor, naringenin, decreases the expression of extracellular matrix induced by TGF-betal in cultured rat hepatic stellate cells. Pharm Res 23: 82-89, 2006.

58. Williams EJ, Benyon RC, Trim N, Hadwin R, Grove BH, Arthur MJ, Unemori EN and Iredale JP: Relaxin inhibits effective collagen deposition by cultured hepatic stellate cells and decreases rat liver fibrosis in vivo. Gut 49: 577-583, 2001. 
59. Iredale JP: Tissue inhibitors of metalloproteinases in liver fibrosis. Int J Biochem Cell Biol 29: 43-54, 1997.

60. Arthur MJ: Fibrogenesis II. Metalloproteinases and their inhibitors in liver fibrosis. Am J Physiol Gastrointest Liver Physiol 279: G245-G249, 2000.

61. Huang CC, Chuang JH, Chou MH, Wu CL, Chen CM, Wang CC, Chen YS, Chen CL and Tai MH: Matrilysin (MMP-7) is a major matrix metalloproteinase upregulated in biliary atresia-associated liver fibrosis. Mod Pathol 18: 941-950, 2005.

62. Xu GF, Li PT, Wang XY, Jia X, Tian DL, Jiang LD and Yang JX: Dynamic changes in the expression of matrix metalloproteinases and their inhibitors, TIMPs, during hepatic fibrosis induced by alcohol in rats. World J Gastroenterol 10: 3621-3627, 2004.

63. Mateescu RB, Rimbas M, Staniceanu F, Zurac S, Dragomir P, Voiosu MR, Tataru M, Zota M and Bucurica S: Histological and nonhistological criteria in the evaluation of liver involvement in chronic hepatitis C. Rom J Intern Med 44: 117-130, 2006.

64. Ratziu V, Bugianesi E, Dixon J, Fassio E, Ekstedt M, Charlotte F, Kechagias S, Poynard T and Olsson R: Histological progression of non-alcoholic fatty liver disease: a critical reassessment based on liver sampling variability. Aliment Pharmacol Ther 26: 821-830, 2007.

65. Sørensen HT, Thulstrup AM, Mellemkjar L, Jepsen P, Christensen E, Olsen JH and Vilstrup H: Long-term survival and cause-specific mortality in patients with cirrhosis of the liver: a nationwide cohort study in Denmark. J Clin Epidemiol 56: 88-93, 2003.

66. Desmet VJ, Knodell RG, Ishak KG, Black WC, Chen TS, Craig R, Kaplowitz N, Kiernan TW and Wollman J: Formulation and application of a numerical scoring system for assessing histological activity in asymptomatic chronic active hepatitis. J Hepatol 38: 382-386, 2003.

67. Regev A, Berho M, Jeffers LJ, Milikowski C, Molina EG, Pyrsopoulos NT, Feng ZZ, Reddy KR and Schiff ER: Sampling error and intraobserver variation in liver biopsy in patients with chronic HCV infection. Am J Gastroenterol 97: 2614-2618, 2002.

68. Rosenberg WM, Voelker M, Thiel R, Becka M, Burt A, Schuppan D, Hubscher S, Roskams T, Pinzani M and Arthur MJ: Serum markers detect the presence of liver fibrosis: a cohort study. Gastroenterology 127: 1704-1713, 2004.

69. Friedman SL: Liver fibrosis - from bench to bedside. J Hepatol 38 (Suppl 1): S38-S53, 2003

70. Bourliere M, Penaranda G, Renou C, Botta-Fridlund D, Tran A, Portal I, Lecomte L, Castellani P, Rosenthal-Allieri MA, Gerolami R, Ouzan D, Deydier R, Degott C and Halfon P: Validation and comparison of indexes for fibrosis and cirrhosis prediction in chronic hepatitis $\mathrm{C}$ patients: proposal for a pragmatic approach classification without liver biopsies. J Viral Hepat 13: 659-670, 2006.

71. Myers RP, Benhamou Y, Imbert-Bismut F, Thibault V, Bochet M, Charlotte F, Ratziu V, Bricaire F, Katlama C and Poynard T: Serum biochemical markers accurately predict liver fibrosis in HIV and hepatitis C virus co-infected patients. AIDS 17: 721-725, 2003.

72. Halfon P, Bourliere M, Deydier R, Botta-Fridlund D, Renou C, Tran A, Portal I, Allemand I, Bertrand JJ, Rosenthal-Allieri A, Rotily M, Sattonet C, Benderitter T, Saint Paul MC, Bonnot HP, Penaranda G, Degott C, Masseyeff MF and Ouzan D: Independent prospective multicenter validation of biochemical markers (fibrotest-actitest) for the prediction of liver fibrosis and activity in patients with chronic hepatitis C: the fibropaca study. Am J Gastroenterol 101: 547-555, 2006.

73. Maor Y, Bashari D, Kenet G, Lubetsky A, Luboshitz J, Schapiro JM, Pénaranda G, Bar-Meir S, Martinowitz U and Halfon P: Non-invasive biomarkers of liver fibrosis in haemophilia patients with hepatitis C: can you avoid liver biopsy? Haemophilia 12: 372-379, 2006.

74. Sène D, Limal N, Messous D, Ghillani-Dalbin P, Charlotte F, Thiollière JM, Piette JC, Imbert-Bismut F, Halfon P, Poynard T and Cacoub P: Biological markers of liver fibrosis and activity as non-invasive alternatives to liver biopsy in patients with chronic hepatitis $\mathrm{C}$ and associated mixed cryoglobulinemia vasculitis. Clin Biochem 39: 715-721, 2006.

75. Kirimlioglu H, Kirimlioglu V and Yilmaz S: Expression of matrix metalloproteinases 2 and 9 in donor liver, cirrhotic liver, and acute rejection after human liver transplantation. Transplant Proc 40: 3574-3577, 2008.

76. Toniutto P, Fabris C, Bitetto D, Falleti E, Avellini C, Rossi E, Smirne C, Minisini R and Pirisi M: Role of AST to platelet ratio index in the detection of liver fibrosis in patients with recurrent hepatitis C after liver transplantation. J Gastroenterol Hepatol 22: 1904-1908, 2007
77. Carvalho-Filho RJ, Schiavon LL, Narciso-Schiavon JL, Sampaio JP, Lanzoni VP, Ferraz ML and Silva AE: Optimized cutoffs improve performance of the aspartate aminotransferase to platelet ratio index for predicting significant liver fibrosis in human immunodeficiency virus/hepatitis $\mathrm{C}$ virus co-infection. Liver Int 28: 486-493, 2008.

78. Lackner C, Struber G, Liegl B, Leibl S, Ofner P, Bankuti C, Bauer B and Stauber RE: Comparison and validation of simple noninvasive tests for prediction of fibrosis in chronic hepatitis $\mathrm{C}$. Hepatology 41: 1376-1382, 2005

79. Sim SJ, Cheong JY, Cho SW, Kim JS, Lim TY, Shin do H, Lim SG, Kim YB, Lee KM, Yoo BM, Lee KJ, Hahm KB and Kim JH: Efficacy of AST to platelet ratio index in predicting severe hepatic fibrosis and cirrhosis in chronic hepatitis B virus infection. Korean J Gastroenterol 45: 340-347, 2005.

80. Nøjgaard C, Johansen JS, Christensen E, Skovgaard LT, Price PA and Becker U: Serum levels of YKL-40 and PIIINP as prognostic markers in patients with alcoholic liver disease. J Hepatol 39: $179-186,2003$

81. Stickel F, Poeschl G, Schuppan D, Conradt C, Strenge-Hesse A, Fuchs FS, Hofmann WJ and Seitz HK: Serum hyaluronate correlates with histological progression in alcoholic liver disease. Eur J Gastroenterol Hepatol 15: 945-950, 2003

82. McHutchison JG, Blatt LM, De Medina M, Craig JR, Conrad A, Schiff ER and Tong MJ: Measurement of serum hyaluronic acid in patients with chronic hepatitis $\mathrm{C}$ and its relationship to liver histology. Consensus Interferon Study Group. J Gastroenterol Hepatol 15: 945-951, 2000.

83. Santos VN, Leite-Mór MM, Kondo M, Martins JR, Nader H, Lanzoni VP and Parise ER: Serum laminin, type IV collagen and hyaluronan as fibrosis markers in non-alcoholic fatty liver disease. Braz J Med Biol Res 38: 747-753, 2005.

84. Naveau S, Poynard T, Benattar C, Bedossa P and Chaput JC: Alpha-2-macroglobulin and hepatic fibrosis. Diagnostic interest. Dig Dis Sci 39: 2426-2432, 1994

85. Poynard T, Aubert A, Bedossa P, Abella A, Naveau S, Paraf F and Chaput JC: A simple biological index for detection of alcoholic liver disease in drinkers. Gastroenterology 100: 1397-1402, 1991.

86. Imbert-Bismut F, Ratziu V, Pieroni L, Charlotte F, Benhamou Y and Poynard T: Biochemical markers of liver fibrosis in patients with hepatitis $C$ virus infection: a prospective study. Lancet 357: 1069-1075, 2001

87. Ngo Y, Munteanu M, Messous D, Charlotte F, Imbert-Bismut F, Thabut D, Lebray P, Thibault V, Benhamou Y, Moussalli J, Ratziu V and Poynard T: A prospective analysis of the prognostic value of biomarkers (FibroTest) in patients with chronic hepatitis C. Clin Chem 52: 1887-1896, 2006.

88. Morali G, Maor Y, Klar R, Braun M, Ben Ari Z, Bujanover Y, Zuckerman E, Boger S and Halfon P: Fibrotest-Actitest: the biochemical marker of liver fibrosis - the Israeli experience. Isr Med Assoc J 9: 588-591, 2007

89. Poynard T, Ratziu V, Charlotte F, Messous D, Munteanu M, Imbert-Bismut $\mathrm{F}$, Massard J, Bonyhay L, Tahiri M, Thabut D, Cadranel JF, Le Bail B and De Ledinghen V: Diagnostic value of biochemical markers (NashTest) for the prediction of non alcoholo steato hepatitis in patients with non-alcoholic fatty liver disease. BMC Gastroenterol 6: 34, 2006.

90. Poordad FF: FIBROSpect II: a potential noninvasive test to assess hepatic fibrosis. Expert Rev Mol Diagn 4: 593-597, 2004

91. Mehta P, Ploutz-Snyder R, Nandi J, Rawlins SR, Sanderson SO and Levine RA: Diagnostic accuracy of serum hyaluronic acid, FIBROSpect II, and YKL-40 for discriminating fibrosis stages in chronic hepatitis C. Am J Gastroenterol 103: 928-936, 2008

92. Adams LA, Bulsara M, Rossi E, De Boer B, Speers D, George J, Kench J, Farrell G, McCaughan GW and Jeffrey GP: Hepascore: an accurate validated predictor of liver fibrosis in chronic hepatitis C infection. Clin Chem 51: 1867-1873, 2005.

93. Calès P, Boursier J, de Lédinghen V, Halfon P, Bacq Y, Leroy V, Dib N, Oberti F, Sawadogo A, Rousselet MC and Lunel F: Evaluation and improvement of a reliable diagnosis of cirrhosis by blood tests. Gastroenterol Clin Biol 32: 1050-1060, 2008.

94. Guha IN, Parkes J, Roderick P, Chattopadhyay D, Cross R, Harris S, Kaye P, Burt AD, Ryder SD, Aithal GP, Day CP and Rosenberg WM: Noninvasive markers of fibrosis in nonalcoholic fatty liver disease: validating the European Liver Fibrosis Panel and exploring simple markers. Hepatology 47: $455-460,2008$

95. Coco B, Oliveri F, Maina AM, Ciccorossi P, Sacco R, Colombatto P, Bonino F and Brunetto MR: Transient elastography: a new surrogate marker of liver fibrosis influenced by major changes of transaminases. J Viral Hepat 14: 360-369, 2007. 
96. Castera L, de Ledinghen V and Couzigou P: Transient elastography vs. blood tests for the diagnosis of cirrhosis: an empiric victory. J Hepatol 16 (In press).

97. Rossi E, Adams LA, Bulsara M and Jeffrey GP: Assessing liver fibrosis with serum marker models. Clin Biochem Rev 28: 3-10, 2007.

98. Dufour DR: Assessment of liver fibrosis: can serum become the sample of choice? Clin Chem 51: 1763-1764, 2005.

99. Bissell DM: Assessing fibrosis without a liver biopsy: are we there yet? Gastroenterology 127: 1847-1849, 2004.

100. Leroy V, Monier F, Bottari S, Trocme C, Sturm N, Hilleret MN, Morel $\mathrm{F}$ and Zarski JP: Circulating matrix metalloproteinases 1, 2, 9 and their inhibitors TIMP-1 and TIMP-2 as serum markers of liver fibrosis in patients with chronic hepatitis C: comparison with PIIINP and hyaluronic acid. Am J Gastroenterol 99: 271-279, 2004.

101. Trocme C, Leroy V, Sturm N, Hilleret MN, Bottari S, Morel F and Zarski JP: Longitudinal evaluation of a fibrosis index combining MMP-1 and PIIINP compared with MMP-9, TIMP-1 and hyaluronic acid in patients with chronic hepatitis $\mathrm{C}$ treated by interferon-alpha and ribavirin. J Viral Hepat 13: 643-651, 2006

102.El-Gindy I, El-Rahman AT, El-Alim MA and Zaki SS: Diagnostic potential of serum matrix metalloproteinase-2 and tissue inhibitor of metalloproteinase- 1 as non-invasive markers of hepatic fibrosis in patients with $\mathrm{HCV}$ related chronic liver disease. Egypt J Immunol 10: 27-35, 2003.
103. El-Shorbagy E, Afefy AF, Ibrahem IA, Mangoud AM, Eissa MH, Sabee EI, Mahrous S, Abdel-Monem A, Ismail A, Morsy TA, Etewa S, Nor Edin E, Mostafa Y, Abouel-Magd Y, El-Sedawy M, Ragab H, El-Tokhy H, Hassan MI, Lakouz K, Abdel-Aziz K, El-Hady G and Saber M: Non-invasive markers and predictors of severity of hepatic fibrosis in HCV patients at Sharkia Governorate, Egypt. J Egypt Soc Parasitol 34 (Suppl 1): 459-578, 2004.

104. Lichtinghagen R, Huegel O, Seifert T, Haberkorn CI, Michels D, Flemming $\mathrm{P}, \mathrm{Bahr} \mathrm{M}$ and Boeker $\mathrm{KH}$ : Expression of matrix metalloproteinase-2 and -9 and their inhibitors in peripheral blood cells of patients with chronic hepatitis C. Clin Chem 46 : 183-192, 2000.

105.Lichtinghagen R, Michels D, Haberkorn CI, Arndt B, Bahr M, Flemming P, Manns MP and Boeker KH: Matrix metalloproteinase (MMP)-2, MMP-7, and tissue inhibitor of metalloproteinase-1 are closely related to the fibroproliferative process in the liver during chronic hepatitis C. J Hepatol 34: 239-247, 2001.

106. Mitsuda A, Suou T, Ikuta Y and Kawasaki H: Changes in serum tissue inhibitor of matrix metalloproteinase-1 after interferon alpha treatment in chronic hepatitis C. J Hepatol 32: 666-672, 2000.

107.Zhang BB, Cai WM, Wengh HL, Hu ZR, Lu J, Zheng M and Liu RH: Diagnostic value of platelet derived growth factor-BB transforming growth factor-beta1, matrix metalloproteinase-1, and tissue inhibitor of matrix metalloproteinase- 1 in serum and peripheral blood mononuclear cells for hepatic fibrosis. World J Gastroenterol 9: 2490-2496, 2003. 